\title{
Concentrações Plasmáticas de Progesterona em Borregas Lanadas e Deslanadas no Período de Abril a Novembro, no Estado de São Paulo ${ }^{1}$
}

\author{
Aya Sasa ${ }^{2}$, Daniela Cristiane Teston ${ }^{3}$, Paula de Almeida Rodrigues ${ }^{5}$, Lia de Alencar Coelho ${ }^{6}$, \\ Edison Schalch 6
}

RESUMO - Objetivou-se com este trabalho o fornecimento de informações sobre o padrão de secreção da progesterona $\left(\mathrm{P}_{4}\right)$ e as características de manifestação do ciclo estral em borregas lanadas e deslanadas, durante o período de abril a novembro, no Estado de São Paulo. Amostras de sangue foram coletadas da veia jugular de 12 borregas das raças Santa Inês (SI), Romney Marsh (RM) e Suffolk (SU), e as concentrações foram determinadas pelo método de radioimunoensaio utilizando-se kits comerciais. O estro foi detectado por machos vasectomizados (impregnados com tinta pó xadrez + óleo comestível na região peitoral) em 31 borregas (10 SI, 11 RM e 10 SU). O estro foi determinado pelo confronto da observação de fêmeas marcadas pelos machos vasectomizados e dos valores de concentrações plasmáticas de progesterona inferiores a $1 \mathrm{ng} / \mathrm{mL}$. Os resultados mostraram que a maioria dos ciclos estrais foi de duração normal (14 - 19 dias) para todas as raças. A duração dos ciclos de duração normal das borregas SU foi inferior aos das borregas SI e RM, as quais não diferiram entre si. Não houve diferença entre as raças na duração dos ciclos curtos (<14 dias) e longos ( 20 - 26 dias). O padrão de secreção de $\mathrm{P}_{4}$ mostrou a presença de ciclos estrais múltiplos (27 - 57 dias) indicando a incidência de ovulações silenciosas. As borregas SI encontravam-se em atividade cíclica reprodutiva apresentando valores que variaram de 0,08 a $7,36 \mathrm{ng} / \mathrm{mL}$, enquanto que as raças $\mathrm{RM} \mathrm{e} \mathrm{SU}$ encontravam-se em atividade somente no período de abril a julho com valores que variaram de 0,13 a $7,05 \mathrm{ng} / \mathrm{mL}$ e de 0,15 a 7,30 ng/mL, respectivamente. De agosto a novembro, estas duas raças encontravam-se em anestro. Conclui-se que, em São Paulo, a raça SI não possui estacionalidade no ciclo reprodutivo como as raças RM e SU.

Palavras-chave: ciclo estral, ovinos, progesterona, raças

\section{Plasma Concentrations of Progesterone in Hair and Wool Ewe Lambs from April to November, in São Paulo State}

\begin{abstract}
The goal of this experiment was to provide information about the pattern of progesterone secretion $\left(\mathrm{P}_{4}\right)$ and on the oestrus cycle characteristics in hair and wool ewe lambs, from April to November, in São Paulo State. Blood samples from jugular vein were collected from 12 ewe lambs Santa Inês (SI), Romney Marsh (RM) and Suffolk(SU) breeds, and the concentrations were determined by radioimmunoassay method, using commercial kits. Oestrus was detected by using vasectomized rams (fitted with raddle crayons + comestible oil on pectoral area) in 31 ewe lambs (10 SI, 11 RM and $10 \mathrm{SU}$ ). The oestrus was determined by confronting the observation of marked females by vasectomized rams and values of plasma progesterone concentrations lower than $1 \mathrm{ng} / \mathrm{mL}$. The results showed that the majority of oestrus cycles were of normal lenght (14 - 19 days) for all breeds. The normal cycles lenght for the SU ewe lambs was shorter than SI and RM, which did not differ from each other. There was no difference for short ( $<14$ days) and long ( 20 - 26 days) oestrus cycles duration between the breeds. The pattern of $\mathrm{P}_{4}$ secretion showed the presence of multiples oestrus cycles ( $27-57$ days) leading to the incidence of silent ovulations. SI ewe lambs were in cyclic activity, showing values from 0.08 to $7.36 \mathrm{ng} / \mathrm{mL}$, while RM and SU breeds were in activity only from April to July with values from 0.13 to $7.05 \mathrm{ng} / \mathrm{mL}$ and from 0.15 to $7.30 \mathrm{ng} / \mathrm{mL}$, respectively. From August to November, these two breeds were in anoestrus. It was concluded that, in São Paulo State, SI breed does not have a stationary on reproductive cycle, as RM and SU breeds
\end{abstract}

Key Words: breeds, oestrus cycle, ovine, progesterone

\section{Introdução}

Durante o primeiro ano de atividade reprodutiva a fertilidade das borregas é baixa comparada à de ovelhas adultas (Dyrmundsson, 1978). Uma série de indicativos demonstra que as fêmeas ovinas continuam sexualmente imaturas por algum tempo após atingirem a puberdade, quando a mesma é definida como a ocorrência do primeiro estro. Alguns dos eventos observados incluem a curta duração do estro e a baixa intensidade de sua manifestação (Hafez, 1952; Dyrmundsson, 1978), bem como a presença de ovu-

\footnotetext{
${ }^{1}$ Projeto financiado pela FAPESP.

${ }_{2}^{2}$ Pós-graduanda em Zootecnia da FZEA/USP. E.mail: ayasasa@hotmail.com, CP 23, CEP 13630-970, Pirassununga-SP, Brasil.

${ }^{3}$ Aluna de Graduação em Zootecnia da FZEA/USP. E.mail: dcteston@yahoo.com

${ }^{4}$ Zootecnista. E.mail: taiscrivellenti@yahoo.com

5 Pós-graduanda em Medicina Veterinária da FMVZ/UNESP. E.mail: parrodrigues@hotmail.com

${ }^{6}$ Docente do Depto de Zootecnia da Faculdade de Zootecnia e Eng. Alimentos - FZEA/USP. E.mail: liac@usp.br; eschalch@usp.br
} 
lações silenciosas (Hare \& Bryant, 1982; Abecia et al., 1996) e de ciclos estrais irregulares ou longos (Hafez, 1952; Bathaei, 1996). Este último evento foi, pioneiramente, relatado por Hafez (1952) que classificou a duração do ciclo estral em simples (até 26 dias) e múltipla (27-57 dias). Os ciclos estrais simples foram divididos em ciclos curtos ( $<14$ dias), normais (14-19 dias) e longos (20-26 dias), enquanto que os múltiplos em duplos (27-37 dias) e triplos (38-57 dias). Esse autor e outros (Dyrmundsson \& Lees, 1972; Quirke, 1978; Bathaei, 1996), posteriormente, assumiram que ovulações sem comportamento de estro (silenciosas) ocorreram entre dois períodos de estros clínicos em ciclos estrais maiores que 26 dias. As presenças de tais ovulações foram confirmadas por Hare \& Bryant (1982) mediante a determinação das concentrações plasmáticas de progesterona.

Em geral, a maioria das raças de ovinos apresenta um modelo de reprodução sazonal com incidência de ciclos estrais concentrada durante o outono e inverno (Hafez, 1952; Sasa et al., 2001). Um dos principais fatores responsáveis por essa estacionalidade é o fotoperíodo, sendo que a sua influência na reprodução das fêmeas tem como interdependência a latitude, em caráter diretamente proporcional. Em latitudes mais elevadas, quando a variação da intensidade luminosa é maior, a estacionalidade reprodutiva está intimamente relacionada com o fotoperíodo, enquanto que em baixas latitudes esta relação é menos pronunciada (Chamineau et al., 1993).

No Brasil, cuja área geográfica estende-se tanto sobre a linha do Equador (Regiões Nordeste e Norte) como sobre uma grande variação de latitudes ao Sul (Região Central, Sudeste e Sul), a duração da estação reprodutiva das ovelhas varia consideravelmente. $\mathrm{Na}$ Região Nordeste, as ovelhas deslanadas ciclam ao longo do ano, podendo ser acasaladas mais de uma vez ao ano (Figueiredo et al., 1980; Girão et al., 1984). Nesta região, a estacionalidade da atividade reprodutiva varia mais em função da temperatura e da nutrição (Simplício et al., 1982; Silva \& Nunes, 1987; Silva et al., 1987). Na Região Sul, vários trabalhados realizados com raças de duplo propósito e especializadas para produção de carne apresentaram uma estação reprodutiva mais restrita a estação de outono (Nunes \& Figueiró, 1975; Silva \& Figueiró, 1980; Ribeiro et al., 1996). Já na região Sudeste, é possível observar certa estacionalidade na atividade reprodutiva nas ovelhas lanadas (Prucolli \& Baccari
Jr., 1967; Roda et al., 1993). Em contrapartida, nessa região, as raças deslanadas não apresentaram estacionalidade da atividade reprodutiva (Traldi, 1990).

No Estado de São Paulo, a atividade reprodutiva das fêmeas das raças Suffolk e Romney Marsh sofre marcada influência do fotoperíodo, enquanto as fêmeas da raça Santa Inês quase não respondem à variação anual fotoperiódica (Rodrigues, 2001). Porém, ainda faz-se necessário um estudo com informações sobre o padrão de secreção de progesterona, bem como as características de manifestação do ciclo estral durante a estação reprodutiva nesta região.

O presente trabalho foi conduzido com o objetivo de estudar o padrão de secreção de progesterona e as características de manifestação do ciclo estral de borregas de raças deslanada (Santa Inês - SI) e lanadas (Romney Marsh - RM e Suffolk - SU) criadas no Estado de São Paulo, no período de abril a novembro.

\section{Material e Métodos}

O experimento foi desenvolvido na Fazenda Experimental da Faculdade de Zootecnia e Engenharia de Alimentos (FZEA) da Universidade São Paulo (USP), Campus de Pirassununga-SP durante o período de abril a novembro de 1999. A região está localizada na latitude $21^{\circ} 59^{\prime}$ Sul, na longitude $47^{\circ} 26^{\prime}$ Oeste e na altitude de $634 \mathrm{~m}$. O clima é classificado como subtropical Cwa Koppen, e o solo como Latossolo Vermelho Escuro Orto. A precipitação pluviométrica anual é de $1300 \mathrm{~mm}$ e a temperatura média de $21^{\circ} \mathrm{C}$, sendo a mínima de $13^{\circ} \mathrm{C}$ e a máxima de $35^{\circ} \mathrm{C}$.

Utilizou-se 31 borregas das raças, deslanada Santa Inês - SI (10) e lanadas, Romney Marsh - RM (11) e Suffolk - SU (10). Os animais permaneceram em três baias, de acordo com a raça, e alimentados com volumoso e concentrado, conforme os requerimentos nutricionais para ovinos em crescimento (NRC, 1985).

Para identificação das fêmeas em estro, em cada baia, introduziu-se um macho vasectomizado (rufião), impregnado com uma mistura de tinta pó xadrez + óleo comestível em sua região peitoral. A cor da tinta foi trocada a cada dez dias e os machos foram revezados entre as baias. Observava-se o grupo duas vezes ao dia, pela manhã e à tarde. As fêmeas que apresentaram-se marcadas na região da garupa ou deixaram-se montar pelo macho foram consideradas em estro.

R. Bras. Zootec., v.31, n.3, p.1150-1156, 2002 
Paralelamente, para determinação das dosagens plasmáticas de progesterona, amostras de sangue foram colhidas da veia jugular de doze animais (quatro de cada raça) em tubos vacutainers heparinizados, a cada 15 dias no período de abril a julho e 30 dias no período de agosto a novembro. As amostras foram centrifugadas a $1500 \mathrm{~g}$ por 15 minutos e o plasma estocado a $-20^{\circ} \mathrm{C}$ até o momento da análise. As concentrações plasmáticas de progesterona foram determinadas pelo método de radioimunoensaio (RIE) em fase sólida, sendo analisadas amostras em duplicatas utilizando-se kits comerciais (COAT-ACOUNT/DPC MEDLAB).

Os parâmetros avaliados foram: variação racial da duração e da incidência de ciclos estrais simples (até 26 dias), os quais dividiram-se em curtos $(<14$ dias), normais (14 - 19 dias) e longos (20 - 26 dias), e múltiplos (27 - 57 dias) que dividiram-se em duplos (27 - 37 dias) e triplos (38 - 57 dias), conforme Hafez (1952). A ocorrência (data) de ovulações silenciosas foi estimada dividindo-se a duração dos ciclos duplos e triplos por dois e três, respectivamente (Bathaei, 1996) e/ou pelas concentrações plasmáticas de progesterona. Considerou-se em anestro as ovelhas que não apresentaram estro num período maior que 57 dias.

O estro foi determinado pela observação de fêmeas marcadas pelos machos vasectomizados e confirmado por valores de concentrações plasmáticas de progesterona inferiores a $1 \mathrm{ng} / \mathrm{mL}$ por um período máximo de 48 horas. Níveis hormonais inferiores a 1 $\mathrm{ng} / \mathrm{mL}$ por período superior a dez dias, as fêmeas eram consideradas em anestro (Minton et al., 1990). Devido à freqüência de colheitas para as dosagens de progesterona ter sido baixa, confrontaram-se os registros de detecção do estro pelos machos vasectomizados e os das dosagens plasmáticas de progesterona para cada animal.

A incidência de ciclos estrais foi analisada pelo teste do Qui-quadrado e as demais variáveis pelo teste não paramétrico Kruskal-Wallis utilizando o procedimento NPAR1WAY no software Statystical Analysis System (SAS). As diferenças entre raças foram analisadas pelo Teste de Dunn.

\section{Resultados e Discussão}

A detecção de estro mediante machos vasectomizados revelou que, durante o período estudado, a maioria dos ciclos estrais observados $(83,3 \%)$ foi considerada simples (até 26 dias) e 56,7\% desses ciclos foram de duração normal (14-19 dias) (Tabela 1). A incidência de ciclos estrais simples e múltiplos foi equivalente entre raças não havendo diferenças $(\mathrm{P}>0,05)$. A baixa incidência de ciclos estrais normais parece ser característica de borregas, mas não de ovelhas (Bathaei, 1996). Este autor, estudando uma raça nativa do Iran, observou que a incidência de ciclos estrais normais foi de 71,6 e $92,1 \%$ para borregas e ovelhas, respectivamente.

Tabela 1 - Incidência (\%) de ciclos estrais curtos (< 14 dias), normais (14-19 dias), longos (20-26 dias) e múltiplos (27-57 dias) em borregas das raças Santa Inês (SI), Romney Marsh (RM) e Suffolk (SU) durante o período de abril a novembro de 1999

Table 1 - Incidence (\%) of short (< 14 days), normal (14-19 day), long (20-26 days) and multiple (27-57 days) oestrus cycles in Santa Inês (SI), Romney Marsh (RM) and Suffolk ewe lambs from April to November, 1999

\begin{tabular}{|c|c|c|c|c|c|c|}
\hline \multirow{3}{*}{$\begin{array}{l}\text { Raças } \\
\text { Breeds }\end{array}$} & \multirow{3}{*}{$\begin{array}{l}\text { Animais (n) } \\
\text { Animals (n.) }\end{array}$} & \multirow{3}{*}{$\begin{array}{l}\text { Total de ciclos estrais (n) } \\
\text { All oestrus cycles (n.) }\end{array}$} & \multicolumn{3}{|c|}{$\begin{array}{l}\% \text { de ciclos estrais }(\mathrm{n}) \\
\% \text { of oestrus cycles }(n .)\end{array}$} & \multirow{3}{*}{$\begin{array}{l}\text { Múltiplos }^{\mathrm{NS}} \\
\text { Multiple }^{N S}\end{array}$} \\
\hline & & & \multicolumn{3}{|c|}{$\begin{array}{l}\text { Simples }^{\mathrm{NS}} \\
\text { Simple }^{N S}\end{array}$} & \\
\hline & & & $\begin{array}{l}\text { Curto } \\
\text { Short }\end{array}$ & $\begin{array}{l}\text { Normal } \\
\text { Normal }\end{array}$ & $\begin{array}{l}\text { Longo } \\
\text { Long }\end{array}$ & \\
\hline SI & 10 & 114 & $11,4(13)$ & $54,4(62)$ & $11,4(13)$ & $22,8(26)$ \\
\hline $\mathrm{RM}$ & 11 & 111 & $16,2(18)$ & $59,5(66)$ & $9,9(11)$ & $14,4(16)$ \\
\hline SU & 10 & 117 & $19,7(23)$ & $56,4(66)$ & $11,1(13)$ & $12,8(15)$ \\
\hline Total & 31 & 342 & $15,8(54)$ & $56,7(194)$ & $10,8(37)$ & $16,7(57)$ \\
\hline
\end{tabular}

NS = Não signiticante $(P>0,05)$.

(n) número.

$N S=$ Not significant $(P>0.05)$.

(n.) number.

R. Bras. Zootec., v.31, n.3, p.1150-1156, 2002 
A duração dos ciclos normais das borregas da raça Suffolk mostrou-se inferior $(\mathrm{P}<0,05)$ aos das raças Santa Inês (SI) e Romney Marsh (RM), que não diferiram entre si $(\mathrm{P}>0,05)$. Não houve diferença $(\mathrm{P}>0,05)$ entre os animais das raças na duração dos ciclos curtos e longos (Tabela 2). A média de duração dos ciclos estrais simples foi de 11,$7 ; 16,4$ e 22,1 dias para os ciclos curtos, normais e longos, respectivamente.

A ocorrência de ciclos estrais múltiplos (27-57 dias) pode ser considerada um indicativo da presença de ovulações silenciosas, as quais foram confirmadas pela análise da progesterona plasmática. A observação de baixa manifestação de estro clínico e presença de ciclos irregulares: curtos ou longos, também tem sido registrada por outros pesquisadores (Hafez, 1952; Dyrmundsson \& Lees, 1972; Quirke, 1978; Bathaei, 1996, Keisler, 1999) pois, todos esses eventos são característicos de fêmeas jovens logo após a puberdade. Ao iniciar o estudo em questão, a idade das fêmeas variava de 9 a 19 meses e todas estavam em início de atividade reprodutiva. As borregas das raças SI e SU nasceram em junho e em julho/agosto de 1998, sendo mantidas em regime semi-intensivo e intensivo, respectivamente. Em contrapartida, as fêmeas da raça RM nasceram em setembro/outubro de 1997 e eram mantidas em regime extensivo. Apesar de serem mais velhas que as demais, estas últimas, provavelmente, atrasaram a puberdade em um ano devido ao sistema de produção adotado na proprieda-

Tabela 2 - Duração (média \pm d.p.) de ciclos estrais curtos (< 14 dias), normais $(14-19$ dias) e longos $(20-26$ dias) em borregas das raças Santa Inês (SI), Romney Marsh (RM) e Suffolk (S)

Table 2 - Lenght (mean \pm s.d.) of short (<14 days), normal (14 - 19 days) and long (20 -26 days) oestrus cycles in Santa Inês (SI), Romney Marsh (RM) and Suffolk ewe lambs

\begin{tabular}{|c|c|c|c|c|}
\hline \multirow[t]{2}{*}{$\begin{array}{l}\text { Raças } \\
\text { Breeds }\end{array}$} & \multirow{2}{*}{$\begin{array}{c}\text { Ciclos } \\
\text { Cycles } \\
\left(\mathrm{n}^{0}\right) \\
(n .)\end{array}$} & \multicolumn{3}{|c|}{$\begin{array}{c}\text { Duração do ciclo estral (dias) } \\
\text { Oestrus cycle lenght (days) }\end{array}$} \\
\hline & & $\begin{array}{l}\text { Curto } \\
\text { Short }\end{array}$ & $\begin{array}{l}\text { Normal } \\
\text { Normal }\end{array}$ & $\begin{array}{l}\text { Longo } \\
\text { Long }\end{array}$ \\
\hline SI & 114 & $12,0 \pm 1,7^{\mathrm{a}}$ & $16,6 \pm 2,1^{\mathrm{a}}$ & $21,9 \pm 2,7^{a}$ \\
\hline $\mathrm{RM}$ & 111 & $11,8 \pm 2,5^{\mathrm{a}}$ & $16,7 \pm 1,9^{\mathrm{a}}$ & $22,0 \pm 2,2^{a}$ \\
\hline SU & 117 & $11,4 \pm 2,2^{\mathrm{a}}$ & $16,0 \pm 2,4^{b}$ & $22,3 \pm 3,8^{a}$ \\
\hline
\end{tabular}

Grupos com diferentes sobrescritos na mesma coluna diferem estatisticamente $(P<0.05)$.

Groups with different superscripts within the same columms are significantly different $(P<.05)$.

R. Bras. Zootec., v.31, n.3, p.1150-1156, 2002 de de origem. Estudo desenvolvido no Nordeste do País demonstrou que, fêmeas manejadas em confinamento, podem atingir a idade à puberdade mais cedo e com peso corporal superior àquelas mantidas em pastagem nativa (Silva et al., 1984). Considerando que as fêmeas Romney Marsh aos 7 9 meses de idade não tinham peso suficiente (menos que $60 \%$ do peso vivo adulto da mesma raça) para atingir a puberdade e, teoricamente, sob nossas condições ambientais, esses animais são estacionais em sua atividade reprodutiva, provavelmente a manifestação do primeiro estro ocorreu na estação reprodutiva subseqüente. De fato, em ovinos a importância do peso corporal na manifestação da atividade cíclica reprodutiva é bastante evidente. Mbayahaga et al. (1998) verificaram que a perda de peso corporal foi o fator mais limitante no retorno da atividade ovariana após o parto de ovelhas criadas na estação seca de Burundi (África).

As concentrações plasmáticas de progesterona das fêmeas SI, RM e SU estão representadas na Figura 1. Esses resultados validaram as observações obtidas mediante a detecção do estro pelos machos vasectomizados. Durante todo o período estudado, as borregas da raça SI encontravam-se em atividade cíclica reprodutiva apresentando valores de progesterona que variaram de 0,08 a $7,36 \mathrm{ng} / \mathrm{mL}$ ao longo do ciclo estral. As fêmeas das raças RM e SU encontravam-se em atividade reprodutiva somente no período de abril a julho com valores plasmáticos que variaram de 0,13 a $7,05 \mathrm{ng} / \mathrm{mL}$ e de $0,15 \mathrm{a} 7,30 \mathrm{ng} / \mathrm{mL}$, respectivamente. No período de agosto a novembro, os valores oscilaram de 0,06 a $0,43 \mathrm{ng} / \mathrm{mL}$ para $\mathrm{RM} \mathrm{e}$ 0,10 a $0,47 \mathrm{ng} / \mathrm{mL}$ para $\mathrm{SU}$ caracterizando que as fêmeas de ambas as raças encontravam-se em anestro.

Segundo Pineda (1989), o ciclo estral pode ser dividido em duas fases: folicular, na qual os folículos crescem e produzem o ovócito, e lútea, caracterizada pela presença de um ou mais corpos lúteos. O comprimento da fase lútea determina o comprimento do ciclo.

O proestro tem duração de dois a três dias e é caracterizado pelo crescimento folicular e secreção de estrógeno, sob estímulo de gonadotrofinas hipofisárias. As concentrações de estrógeno aumentam progressivamente no sangue, e estão associadas com alterações nos órgãos reprodutivos, como aumento no suprimento sangüíneo no trato genital (Jainudeen \& Hafez, 1993). As ovelhas não apresentam sinais evidentes durante o proestro, entretanto com a aproximação do estro, a vulva incha, o vestíbu- 

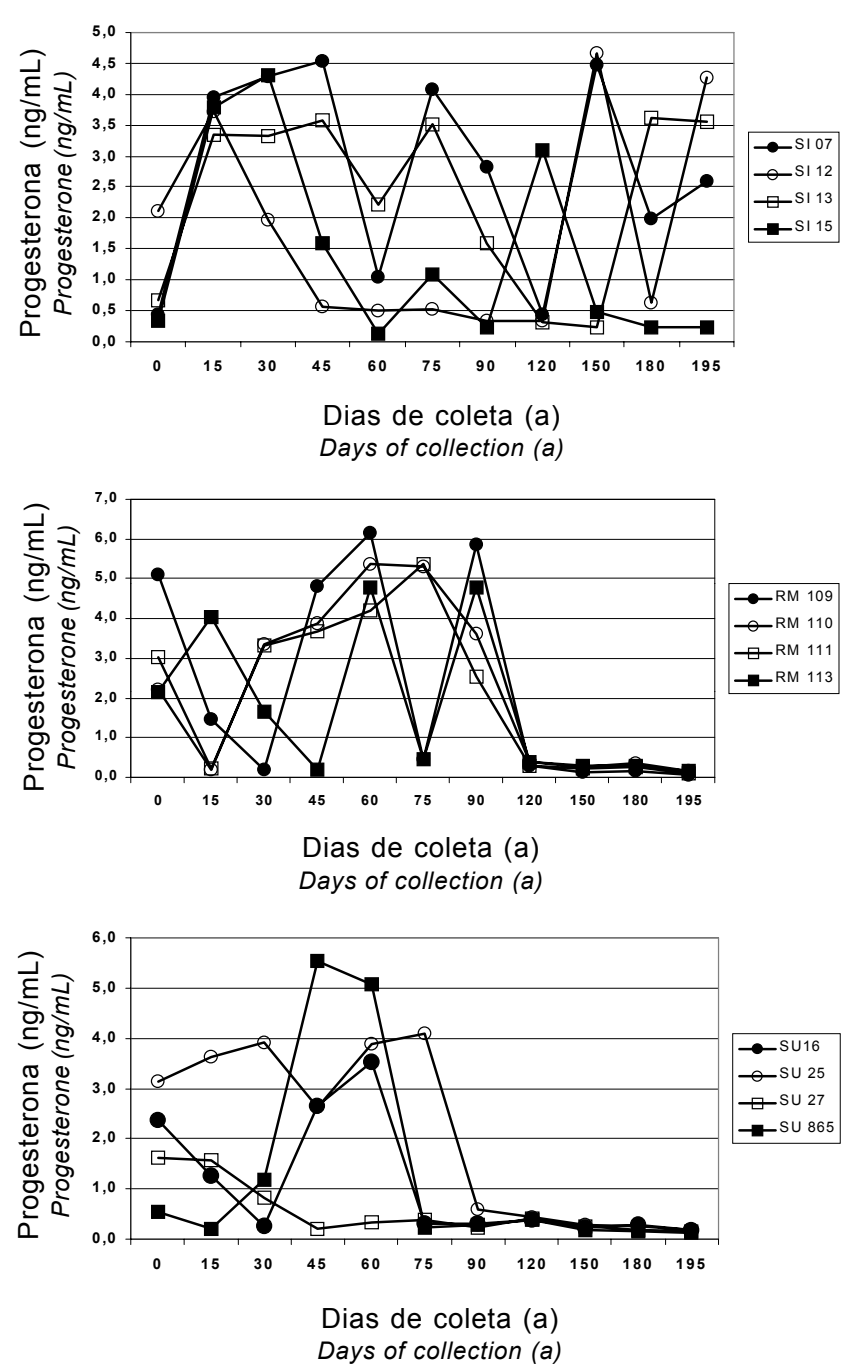

Figura 1 - Concentrações plasmáticas de progesterona de borregas Santa Inês - SI (a), Romney Marsh - RM (b) e Suffolk -SU (c) durante o período de abril a novembro de 1999.

Figure 1 - Plasma progesterone concentration in Santa Inês SI (a), Romney Marsh - RM (b) and Suffolk - SU (c) ewe lambs from April to November, 1999.

lo torna-se hiperêmico e as glândulas da cérvix e vagina produzem secreção serosa que aparece como uma descarga vaginal (Pineda, 1989).

O estro varia de 20 a 36 horas, com média de 26 horas (Pineda, 1989; Lindsay, 1991; Jainudeen \& Hafez, 1993). A ovulação é espontânea e ocorre no final do estro, cerca de 24-27 horas após o início. Ovulações duplas e triplas são comuns, e estas ocorrem dentro de 2 horas após a primeira ovulação (Lindsay, 1991).

Lamming \& Mann (1995) descreveram que o estímulo hormonal para o estro é o estradiol, mas um período de exposição a progesterona, de 6-8 dias é essencial para que a fêmea seja sensível ao estrógeno. Estes autores relacionaram a ocorrência de ovulação silenciosa no início da estação reprodutiva em ovelhas adultas e no início da puberdade, com a falta de progesterona. Assim, enfatizaram que a progesterona é necessária para a expressão do comportamento estral e é fornecida pelo corpo lúteo formado na primeira ovulação silenciosa. O metaestro é definido como o período de formação do corpo lúteo, e para fins práticos, é incluído no diestro (Pineda, 1989).

$\mathrm{O}$ diestro ou fase lútea é a dominante no ciclo estral da ovelha, e dura 12 a 14 dias. Embriões viáveis devem estar presentes no útero até o dia 13 do diestro para fornecer sinal luteotrópico (Pineda, 1989). Se não há embriões viáveis presentes, o corpo lúteo regride rapidamente sob a influência da PGF2a, e a ovelha inicia outro ciclo (Zarco et al., 1988). Este processo repete-se durante subseqüentes ciclos até o final da estação reprodutiva, se a ovelha não se tornar prenhe.

De acordo com Minton et al. (1990), valores plasmáticos de progesterona inferiores a $1 \mathrm{ng} / \mathrm{mL}$ podem caracterizar as fases de estro ou de anestro, enquanto valores superiores a $3 \mathrm{ng} / \mathrm{mL}$ caracterizam a fase de diestro (luteal) ou gestação. A fase de anestro diferencia-se da fase de estro quando as concentrações de progesterona permanecem baixas por um período superior a dez dias. Coelho et al. (2000), trabalhando com os mesmos animais do estudo em questão, verificaram que as médias de concentrações plasmáticas de progesterona durante as fases do ciclo estral das fêmeas SI, RM e SU foram de 0,$45 ; 0,30$ e $0,39 \mathrm{ng} / \mathrm{mL}$ no estro, 1,$64 ; 1,91$ e $1,88 \mathrm{ng} /$ $\mathrm{mL}$ no metaestro, 4,$30 ; 4,86$ e $4,33 \mathrm{ng} / \mathrm{mL}$ no diestro e 2,$16 ; 2,33$ e $1,47 \mathrm{ng} / \mathrm{mL}$ no proestro.

No estudo em questão, a verificação do anestro das fêmeas RM e SU foi realizada mediante o confronto dos resultados obtidos com a detecção do estro pelos machos vasectomizados e as concentrações plasmáticas de progesterona. Os resultados aqui apresentados sugerem que a atividade cíclica reprodutiva de borregas deslanadas e lanadas apresentou diferenças com relação à incidência de ciclos estrais ao longo do período estudado.

Prucolli \& Baccari Jr. (1967) verificaram a incidência máxima de estros, para raças lanadas, no final da primavera e início de verão enquanto que, na mesma região, Roda et al. (1993), testando acasalamentos a cada oito meses, observaram que 
somente $10 \%$ das fêmeas Suffolk estudadas apresentaram cinco partos em quatro anos (intervalo de parto $=9,6$ meses) confirmando a existência de estacionalidade reprodutiva nessa raça. Uma maior incidência de estros durante o outono, também foi observada no Rio Grande do Sul em fêmeas Romney Marsh (Mies Filho \& Ramos, 1960; Figueiredo et al., 1980).

Em contrapartida, as raças deslanadas não apresentam qualquer estacionalidade da atividade reprodutiva (Traldi, 1990). Um estudo realizado com fêmeas deslanadas no México, confirmou a falta de estacionalidade reprodutiva das fêmeas das raças Pelibuey e Blackbelly podendo as mesmas serem utilizadas em sistema intensivo de coberturas de duas estações anuais (Rodríguez et al., 1998). A incidência de ciclos estrais das borregas da raça Santa Inês manteve-se regular durante o período estudado (abril a novembro) enquanto que nas borregas das raças Suffolk e Romney Marsh essa incidência diminuiu a partir de agosto.

\section{Conclusões}

Fêmeas da raça Santa Inês não apresentaram estacionalidade reprodutiva com maior uniformidade na distribuição de ciclos estrais ao longo do períodoestudado.

A atividade cíclica reprodutiva das fêmeas das raças Romney Marsh e Suffolk foi interrompida a partir de agosto.

As atividades cíclicas reprodutivas das fêmeas lanadas (Romney Marsh e Suffolk) e deslanadas (Santa Inês) foram caracterizadas pela presença de ciclos estrais irregulares (curtos, longos e múltiplos) e de ovulações silenciosas.

\section{Literatura Citada}

ABECIA, J.A.; FORCADA, F.; ZARAZAGA, L. et al. The incidence of luteal activity, as determined by peripheral plasma progesterone concentration, before the onset of the breeding season in the Rasa Aragonesa breed of sheep. Brazilian Veterinary Journal, v.152, n.353-355, 1996.

BATHAEI, S. Breeding season and oestrous activity of Iranian fat-tailed Mehraban ewes and ewe lambs. Small Ruminant Research, v.22, p.13-23, 1996.

CHAMINEAU, P.; BERTHELOT, X.; MALPAUX, B. et al. La maîtrise de la reproduction par la photopériode et la mélatonine chez les mammífères d'élevage. Cashiers Agriculture, v.2, p.81-92, 1993.

COELHO, L.A.; RODRIGUES, P.A.; SASA, A. et al. Concentrações plasmáticas de progesterona em borregas lanadas e deslanadas durante a estação reprodutiva. In: REUNIÃO
ANUAL DA SOCIEDADE BRASILEIRA DE ZOOTECNIA, 37., 2000, Viçosa. Anais...Viçosa: Sociedade Brasileira de Zootecnia, 2000. CD ROM

DYRMUNDSSON, Ó.R. Studies on the breeding season of Icelandic ewes and ewes lambs. Journal of Agricultural Science, v.90, p.275-281, 1978.

DYRMUNDSSON, Ó.R.; LEES, J.L. Attainment of puberty and reproductive performance in Clun Forest ewe lambs. Journal of Agricultural Science, v.78, p.39-45, 1972.

FIGUEIREDO, E.A.D.; OLIVEIRA, E.R.; BELLAVER, C. Performance dos ovinos deslanados no Brasil. Sobral, EMBRAPA - CNPC, 1980. 32p (Circular Técnica, 01).

GIRÃO, R.N.; MEDEIROS, L.P.; GIRÃO, E.S. Índices produtivos de ovinos da raça Santa Inês no Estado do Piauí. Teresina: EMBRAPA - UEPAE, 1984. 5p.

HAFEZ, E.S.E. Studies on the breeding season and reproduction of the ewe. Journal of Agricultural Science, v.42, p.189$265,1952$.

HARE, L.; BRYANT, M.J. Characteristics of oestrous cycles and plasma progesterone profiles of young female sheep during their first breeding season. Animal Production, v.35, p.1-7, 1982.

JAINUDEEN, M.R.; HAFEZ, E.S.E. Sheep and goat. In: HAFEZ, E.S.E. (Ed.) Reproduction in farm animals. 6.ed. Philadelphia: Lea \& Fabiger, 1993. p.330-342.

LAMMING, G.E.; MANN, G.E. Control of endometrial oxytocin receptors and prostaglandin $\mathrm{F}_{2}$ a production in cows by progesterone and oestradiol. Journal of Reproduction and Fertility, v.103, p.69-73, 1995.

LINDSAY, D.R. Reproduction in the sheep and goat. In: CUPPS, P.T. (Ed.) Reproduction in domestic animals. 4.ed. San Diego: Academic Press, 1991. p.491-515.

KEISLER, D.H. Sheep and goats In: KNOBIL, E.; NEILL, J.D. (Eds.) Encyclopedia of reproduction. California: Academic Press, 1999. v.4. p.479-492.

MBAYAHAGA, J.; MANDIKI, S.N.M.; BISTER, J.L. et al. Body weight, oestrous and ovarian activity in local Burundian ewes and goats after parturition in the dry season. Animal Reproduction Science, v.51, p.289-300, 1998.

MIES FILHO, A.; RAMOS, A.A Ciclo estral de ovelhas no Brasil. Revista da Escola Agronômica e Veterinária da UFRS, v.3, p.57-63, 1960.

MINTON, J.E.; COPPINGER, T.R.; SPAETH, C.W. et al. Poor reproductive response of anestrous Suffolk ewes to ram exposure is not due to failure to secrete luteinizing hormone acutely. Journal of Animal Science, v.69, p.33114-3320, 1990.

NATIONAL RESEARCH COUNCIL - NRC. Nutrient requirements of sheep. 6 .ed. Washington, D.C.: National Academic Press, 1985.

NUNES, J.F.; FIGUEIRÓ, P.R.P. Fatores que afetam o comportamento reprodutivo em ovelhas Corriedale e Polwarth. Revista Ciência Rural, v.5, n.4, p.301-307, 1975.

PINEDA, M.H. Reproductive patterns of sheep and goat. In: McDONALD, L.E. (Ed.) Veterinary endocrinology and reproduction. 4.ed. Philadelphia: Lea \& Fabiger, 1989. p.428-447.

PRUCOLLI, J.O.; BACCARI Jr., F.L. Estudos sobre estação de monta em ovinos no Estado de São Paulo. Boletim da Indústria Animal, v.24, p.75-80, 1967.

QUIRKE, J.F. Onset of puberty and oestrus activity in Galway, Finnish Landrace and Finn-cross ewe lambs during their first breeding season. Journal of Agriculture Research, v.17, p.15-23, 1978.

R. Bras. Zootec., v.31, n.3, p.1150-1156, 2002 
RIBEIRO, E.L.A.; ROCHA, M.A.; SILVA, L.F. Aspectos reprodutivos em ovelhas Hampshire Down submetidas à monta contínua na região Norte do Paraná. Revista Brasileira de Zootecnia, v.25, n.4, p.637-646, 1996.

RODA, D.S.; SANTOS, L.E.; CUNHA, E.A. et al. Desempenho de ovinos em sistema de acasalamento a cada oito meses. Boletim da Indústria Animal, v.50, n.01, p.49-54, 1993.

RODRIGUES, P.A. Avaliação da sazonalidade reprodutiva e perfil secretório de melatonina em ovelhas (Ovis aries) das raças Romney Marsh, Suffolk e Santa Inês. Botucatu: Universidade Estadual Paulista, 2001. 82p. Tese (Doutorado) Universidade Estadual Paulista, 2001.

RODRÍGUEZ, R.O.L.; HEREDIA, A.M.; QUINTAL, M.A. et al. Productivity of Pelibuey and Blackbelly ewes manted at yearly and 8-monthly intervals over six years. Small Ruminant Research, v.30, p.177-184, 1998.

SASA, A.; TESTON, D.C.; SILVA, E.C.F. et al. Perfil plasmático de progesterona e incidência mensal de ovulações silenciosas em borregas lanadas e deslanadas criadas no Estado de São Paulo. In: CONGRESSO BRASILEIRO DE ZOOTECNIA ZOOTEC, 11., Goiânia, 2001. Anais...Goiânia: ZOOTEC, 2001. p. 16.

SILVA, A.E.D.F.; NUNES, J.F.; SANCHEZ, O. et al. Efeito do manejo nutricional sobre a taxa de ovulação e folículos, no decorrer do ano, em ovinos deslanados no Nordeste do Brasil. Pesquisa Agropecuária Brasileira, v.22, n.6, p.635-645, 1987.

SILVA, A.E.D.F.; NUNES, J.F. Estacionalidade na atividade sexual e qualidade do sêmen nos ovinos deslanados das raças Santa Inês e Somalis Brasileira. Sobral: EMBRAPA - CNPC, 1987. 14p.

SILVA, A.E.D.F.; NUNES, J.F.; RIERA, G.S. et al. Influência da nutrição na atividade ovariana e após a puberdade em ovinos das raças deslanadas. In: SIMPÓSIO NACIONAL DE REPRODUÇÃO ANIMAL, 5., 1984, Belo Horizonte. Anais... Colégio Brasileiro de Reprodução Animal, 1984. p.319.
SILVA, O.L.; FIGUEIRÓ, P.R.P. Efeito da época de cobertura sobre a fertilidade de ovelhas e mortalidade de cordeiros na raça Corriedale. In: REUNIÃO ANUAL DA SOCIEDADE BRASILEIRA DE ZOOTECNIA, 17., 1980, Fortaleza. Anais... Viçosa, MG: Sociedade Brasileira de Zootecnia, 1980. p.127.

SIMPLÍCIO, A.A.; RIERA, G.S.; NELSON, E.A. et al. Seasonal variation in the seminal and testicular characteristics of Brazilian Somalis rams in the semi-aris climate of tropical northeast Brazil. Journal of Reproduction and Fertility, v.66, n.2, p.735-738, 1982.

TRALDI, A.S. Produção de ovinos. Aspectos reprodutivos dos ovinos. Performance reprodutiva dos ovinos deslanados no Brasil. Jaboticabal: Fundação Universidade Estadual Paulista, 1990. p.81-124.

ZARCO, L.; STABENFELDT, G.H.; QUIRKE, J.F. et al. Release of prostaglandin $\mathrm{F}_{2} 2 \alpha$ and the timing of events associated with luteolysis in ewes with oestrous cycles of different lengths. Journal of Reproduction and Fertility, v.83, p.517-526, 1988. 